\title{
Is It Necessary to Perform Surgical Staging in Patients with Giant Immature Ovarian Teratomas Mimicking Mature Cystic Teratoma at Frozen Section
}

\author{
Ismail Guler ${ }^{1}$, Ahmet Turp ${ }^{1}$, Cagatay Taskiran ${ }^{1}$, Anıl Onan ${ }^{1}$, Hayriye Tatli², \\ Haldun Guner ${ }^{1}$, Bulent Tiras ${ }^{1}$
}

\section{Article History:}

Received July 2013

Accepted September 2013

Available online September 2013

\section{Keywords:}

Dermoid Tumors

Frozen Section

Huge Teratoma

Immature Teratoma

Tumor Markers

Corresponding Author:

Ismail Guler, Gazi University School of Medicine, Department. of Obstetrics and Gynecology,

Ankara, Turkey.

Tel: + 903122025918

Email: ismailguler@gazi.edu.tr

\begin{abstract}
:
Giant mature teratomas ( $>20 \mathrm{~cm}$ in diameters) sometimes may contain malignant immature elements or tissues. These small foci of immature tissues could be missed at frozen section resulting inadequate initial surgical intervention. There is no large series in the literature either showing the accuracy of frozen section on huge ovarian teratomas or concerning the adequate surgical approach at the initial surgery for giant immature teratomas diagnosed as mature cystic teratomas at frozen section in patients with elevated tumor markers. We presented a case with unilateral giant immature ovarian teratoma and peritoneal gliomatosis which diagnosed as mature cystic teratoma at frozen section. Although elevated tumor markers (CA-125, AFP, CA-19,9 CEA, and lactate dehydrogenase), ascites and peritoneal implants were suggested malignant disease, staging surgery was not performed due to the benign report of frozen section. Since the patients having peritoneal implants of mature glial tissue have an excellent prognosis regardless of the grade of the ovarian teratomas, it may be suggested that surgical staging at the initial operation may not be performed in patients with giant immature teratoma diagnosed as mature teratoma at frozen section despite to the elevated tumor markers, presence of ascites or mature peritoneal implants. seems that using it in infertile patients has beneficial effects.
\end{abstract}

1- Gazi University School of Medicine, Department of Obstetrics \& Gynecology, Ankara, Turkey.

2- Gazi University School of Medicine, Department of Pathology, Ankara, Turkey. 


\section{Introduction:}

Teratomas are germ cell-derived tumors, representing $15 \%$ of all ovarian neoplasms, and they are classified as mature cystic, mature solid, and immature according to the histopathological characteristics. Benign cystic teratomas are relatively common tumors in reproductive age women, but can occur over a wide age range. Immature teratomas differ from mature cystic teratomas in that they are much less common (1\% of ovarian teratomas), and are histologically distinguished by the presence of immature or embryonic tissues (1). Small foci of these immature tissues of giant teratomas might be missed at frozen section. This causes an additional operation for surgical staging, and the patient is subjected to the morbidities of reoperation. Ostensibly, full surgical staging at the initial operation may be reasonable in cases diagnosed as giant mature teratomas at frozen section with elevated tumor markers. There is no large series in the literature either showing the accuracy of frozen section of huge ovarian teratomas or concerning the adequate surgical approach at the initial surgery for giant immature teratomas diagnosed as mature cystic teratomas at frozen section in patients with elevated tumor markers. There are only a few reports on this subject in the published literature (2, $3)$. In this report we described a case which was diagnosed as immature ovarian teratoma (grade 1) with benign gliomatosis peritonei, mimicking huge ovarian mature cysic teratoma at frozen section, with elevated tumor markers including CA-125, alpha-fetoprotein (AFP), CA19-9, and carcinoembryonic antigen (CEA) and presence of an ascites.

\section{Case Report:}

A 25 years' old patient, gravida 0, was admitted to our department with abdominal discomfort, pain, and an enlarging abdomino-pelvic mass within the last month. On abdominal examination there was a palpable mass extending from the pelvis to approximately $5 \mathrm{~cm}$ above the umbilicus. The mass was smooth and partially mobile. Ultrasonography and computerized tomography revealed a 20x25 $\mathrm{cm}$ left adnexal multiseptated tumor including cystic and solid components with ascites. The level of serum CA-125 was 281 $\mathrm{U} / \mathrm{mL}$, AFP was $314 \mathrm{ng} / \mathrm{mL}, \mathrm{CA}-19.9$ was 638 $\mathrm{U} / \mathrm{mL}$, CEA was $12.1 \mathrm{mg} / \mathrm{L}$, and lactate dehydrogenase was 125 U/L. Electrolytes, liver function tests, urine analysis and complete blood count were within the normal limits. Therefore, she underwent exploratory laparotomy via midline incision. In the exploration, the uterus, the right ovary, and the both of the fallopian tubes were normal. The left ovary was transformed into a solid and cystic tumor; with the largest diameter of $25 \mathrm{~cm}$ (Figure 1). Approximately $250 \mathrm{cc}$ ascitic fluid was aspirated. Abdomino-pelvic peritoneal surfaces and omentum were carefully examined, only a few peritoneal implants approximately $4 \mathrm{~cm}$ in diameter, in the pouch of Douglas were found. No visible or palpable lymph nodes were detected. Left adnexectomy was performed, and the all peritoneal implants were resected. Frozen section revealed a mature cystic teratoma of left ovary with mature glial peritoneal implants of the Douglas pouch. No abnormality was detected in cytological analysis of ascitic fluid. The paitent was recovered without any complication, and discharged from the hospital on the 4th postoperative day. The final pathology revealed a grade 1 immature cystic teratoma of the left ovary, and peritoneal mature glial implants by the diagnosis of the immature foci of neural elements on 5 of 65 sections of the tumor (Figure 2). However, foci of immature neural tissue in the ovarian mass had not been detected at frozen section. After the extensive discussion of the literature with the patient neither additional staging surgery was performed nor was adjuvant therapy given. At the first year follow-up visit she had normal tumor markers, without any sign of recurrent disease at pelvic exam and imaging studies including ultrasonography and computerized tomography.

\section{Discussion:}

Immature ovarian teratoma is one of the malignant germ cell tumor of the ovary besides dysgerminoma, endodermal sinus tumor, choriocarcinoma, and embryonal 
carcinoma. This neoplasm may contain ectodermal, mesodermal, and endodermal tissues, in any combination, and it is graded histologically from grade 1 to 3 according to the amount of immature neural elements (4). The 5-year overall survival rates have been noted as $95 \%$ and $85 \%$, for grade 1 and grade 2-3 tumours, respectively (5). Grade 2 and 3 has been placed in the same category since treatment for these patients is identical. Since immature teratomas mostly affect women at younger ages, the main problem related with the surgical therapy is preservation of fertility. There is no large series in the literature either showing the accuracy of frozen section on huge ovarian teratomas or concerning the adequate surgical approach at the initial surgery for giant immature teratomas diagnosed as mature cystic teratomas at frozen section in patients with elevated tumor markers. However, the limitations of frozen section on huge ovarian teratomas were reported in a few case reports (Table 1). Einarsson et al. reported 13 years old girl having $20 \mathrm{~cm}$ right ovarian mass with normal levels of tumor markers. Although the tumor was diagnosed as mature cystic teratoma at frozen section, left salpingo-oophorectomy and comprehensive surgical staging was performed. The final pathology was grade 1 and stage 1 immature cystic teratoma. The authors concluded that, the patients having apparently mature cystic teratomas larger than $8 \mathrm{~cm}$ should undergo peritoneal biopsies, omental sampling, and ipsilateral pelvic lymph node sampling at initial operation due to the inadequacy of frozen section (2). On the contrary Beiner et al. presented eight patients who were treated with only cystectomy for ovarian immature teratoma of which the frozen diagnoses were mature teratoma (3). No additional staging surgery was performed, but adjuvant chemotherapy was given to the 4 patients having grade 2 or 3 disease. None of the patients had recurrence during median follow-up period of 56.5 months. These results were comparable with the other studies which reported that salpingooophorectomy and close monitoring are sufficient therapeutic approach even for patients with grade 2 or 3 immature teratomas (6-8).

The existance of yolk sac tumor (YST) within immature teratomas has been recognized as both the source of AFP and the major predictor of stage, grade, and recurrence (9). In the case series of Heifetz et al, $96 \%$ of the patients whose tumors had foci of YST, initial AFP concentrations were elevated above the normal value and it is demonstrated that elevations of serum AFP concentrations greater than $100 \mathrm{ng} / \mathrm{dL}$ almost always associated with the presence of foci of YST. Contrarily, in our case, elevated CA-125, AFP, CA-19,9, lactate dehydrogenase, CEA levels are suspecting the inclusion of more than one immature tissues but there was only small foci of immature neuronal tissue at final histopathologic report. In another report, elevation of AFP was also seen without any foci of YST (10). In this report, Hamada et al. presented a case aged 9 years with elevated alpha-fetoprotein (235 $\mathrm{ng} / \mathrm{ml})$. At the initial operation salpingooophorectomy and partial omentectomy was performed for $21 \times 17 \times 12 \mathrm{~cm}$ ovarian mass and 0.1-0.3 cm omental implants. The primary pathology revealed mature cystic teratoma, but after 14 weeks of the initial operation AFP was re-elevated $(214 \mathrm{ng} / \mathrm{ml})$. Therefore, recurrent tumor (derived from the remaining implants of the cull-de-sac peritoneum) was resected with a partial omentectomy. Pathological examinations of the recurrent tumor and omental implants have revealed immature teratomas grade 1 and grade 0 , respectively. This report emphasizes the importance of accurate histological grading and wide resection of the peritoneal implants. Because of the remaining implants may include immature teratomatous or germ cell elements even they were diagnosed as mature at frozen section, extensive resection of peritoneal implants is essential at the initial operation especially in patients with elevated tumor markers. The sufficiency of resection of peritoneal implants can be determined by observing the dropping levels of tumor markers.

It can be concluded that most of the grade 1 immature teratomas could be falsely diagnosed as mature cystic teratoma due to 
missing of the small foci of immature tissues at frozen section. Since the patients having peritoneal implants of mature glial tissue have an excellent prognosis regardless of the grade of the ovarian teratomas (11), it may be suggested that surgical staging at the initial operation may not be performed in patients with giant immature teratoma diagnosed as mature teratoma at frozen section despite to the elevated tumor markers, presence of ascites or mature peritoneal implants.

In conclusion, the convenient method of therapy in patients with giant immature teratomas mimicking mature cystic teratomas at frozen section, even with elevated tumor markers, may be cystectomy or unilateral salpingo-oophorectomy with a wide resection of peritoneal implants at the initial operation.

\section{Conflict of interest statement:}

We declare that we have no conflict of interest.

Figures :

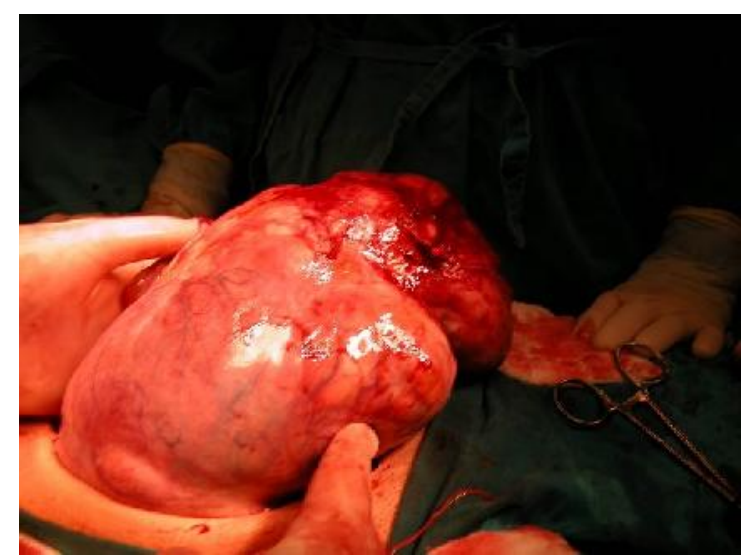

Figure 1

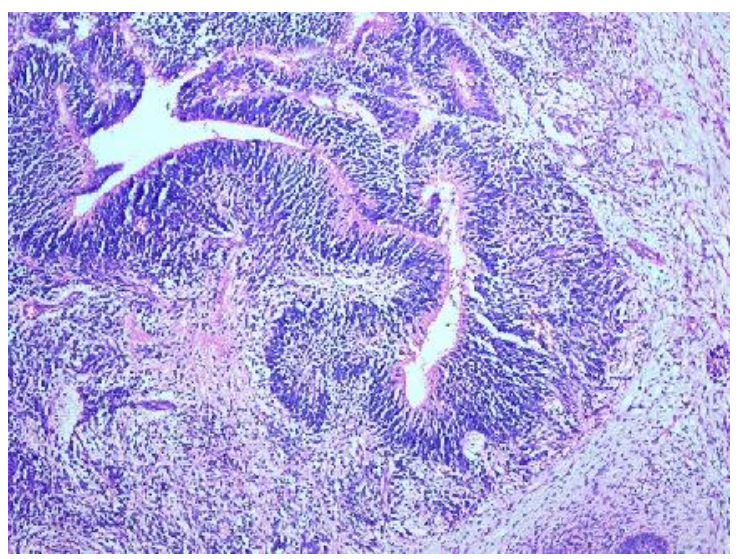




\begin{tabular}{|c|c|c|c|c|c|c|c|c|c|c|c|c|}
\hline 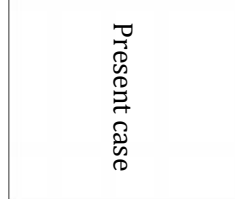 & 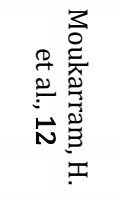 & & & & & & & & 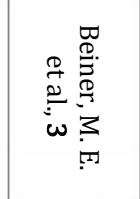 & 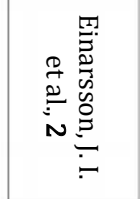 & 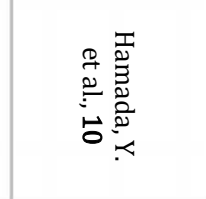 & 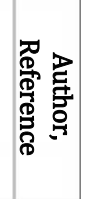 \\
\hline 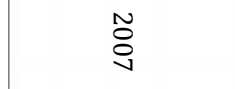 & $\begin{array}{l}\tilde{\Xi} \\
\text { ڤ̆ }\end{array}$ & & & & & & & & $\begin{array}{l}\tilde{a} \\
\stackrel{8}{\perp}\end{array}$ & 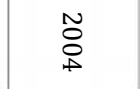 & $\begin{array}{l}\vec{b} \\
\stackrel{\infty}{\infty}\end{array}$ & $\underset{\Phi}{\overparen{্}}$ \\
\hline$\vdash$ & $\bullet$ & $\begin{array}{l}\infty \\
\dot{\infty}\end{array}$ & $\stackrel{\infty}{\dot{v}}$ & $\begin{array}{l}\infty \\
o ̛\end{array}$ & $\begin{array}{l}\infty \\
\dot{i} \\
\text { in }\end{array}$ & $\stackrel{\infty}{\not}$ & $\stackrel{\infty}{\dot{\omega}}$ & $\stackrel{\infty}{\stackrel{\infty}{\sim}}$ & $\stackrel{\infty}{\dot{\sim}}$ & $\vdash$ & $\vdash$ & 医 \\
\hline$\tilde{\tilde{N}}$ & $\stackrel{\omega}{\sqcup}$ & $\tilde{v}$ & $\vec{\omega}$ & $\tilde{\infty}^{\infty}$ & $\tilde{o}$ & $\tilde{\tilde{u}}$ & $\tilde{v}$ & $\stackrel{\omega}{o}$ & $\overrightarrow{0}$ & $\vec{\omega}$ & 0 & 洜 \\
\hline 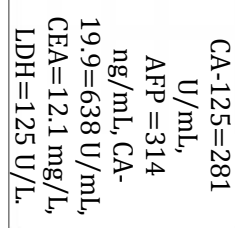 & 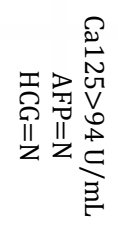 & $\frac{z}{p}$ & $\frac{z}{s}$ & $\frac{z}{p}$ & $\frac{z}{p}$ & $\underset{j}{z}$ & $\frac{z}{p}$ & 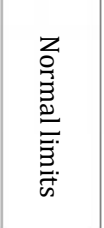 & $\frac{z}{p}$ & 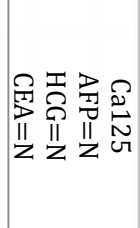 & 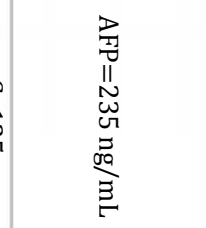 & 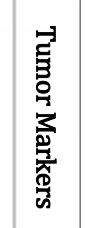 \\
\hline 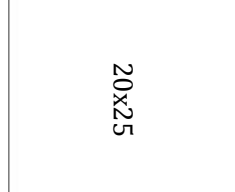 & $\begin{array}{l}\underset{\tilde{x}}{\tilde{x}} \\
\underset{\infty}{x}\end{array}$ & $\underset{s}{z}$ & $\Xi$ & $\vec{v}$ & $\frac{z}{p}$ & $\frac{z}{p}$ & $\tilde{\tilde{N}}$ & $\underset{D}{z}$ & $\frac{z}{p}$ & $\tilde{O}$ & $\begin{array}{l}\stackrel{N}{\vec{x}} \\
\stackrel{x}{x} \\
\stackrel{N}{N}\end{array}$ & 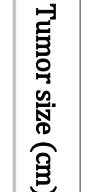 \\
\hline 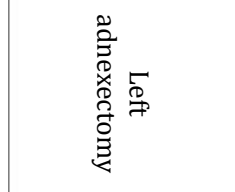 & 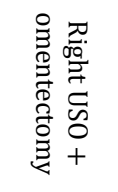 & 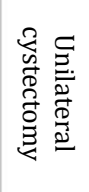 & 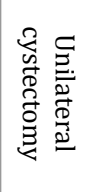 & 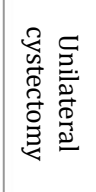 & 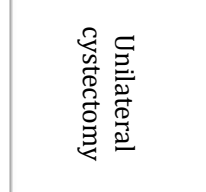 & 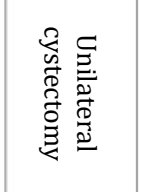 & 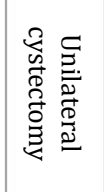 & 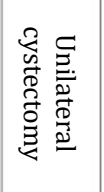 & 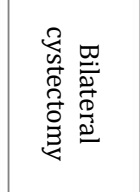 & 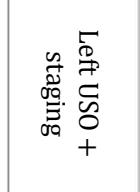 & 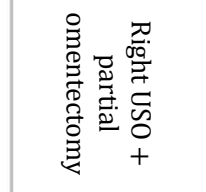 & 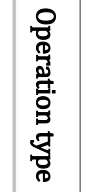 \\
\hline 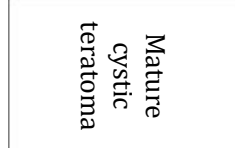 & $\underset{s}{z}$ & 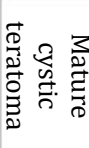 & 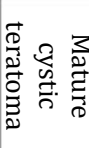 & 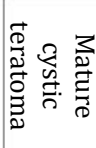 & 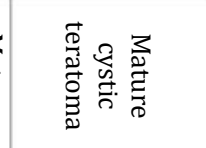 & 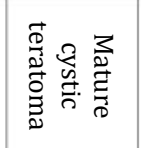 & 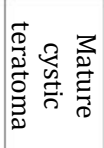 & 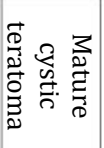 & 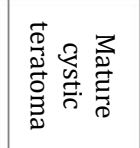 & 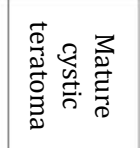 & 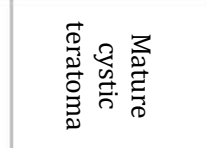 & 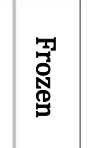 \\
\hline 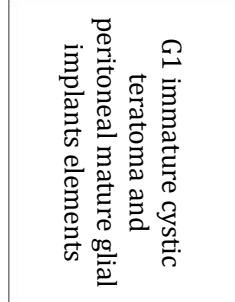 & 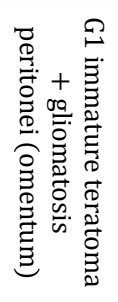 & 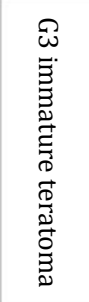 & 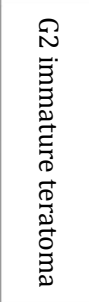 & 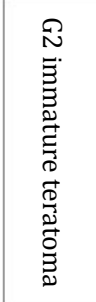 & 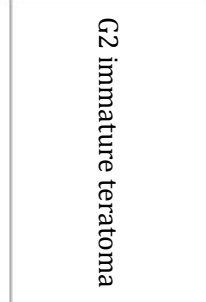 & 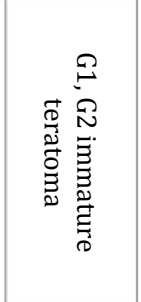 & 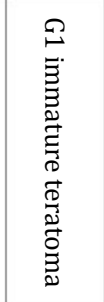 & 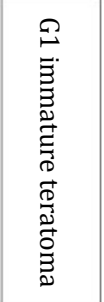 & 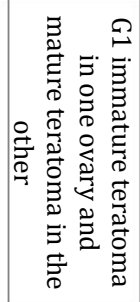 & 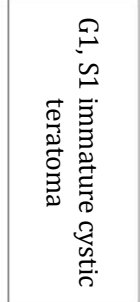 & 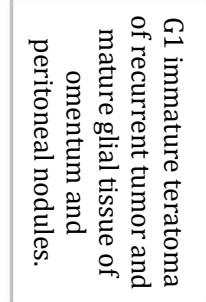 & 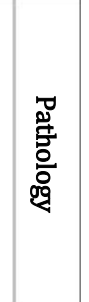 \\
\hline $\begin{array}{l}\text { za } \\
\stackrel{0}{\sigma}\end{array}$ & $\begin{array}{l}z \\
\stackrel{0}{\sigma} \\
\stackrel{0}{0}\end{array}$ & 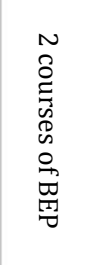 & $\begin{array}{l}\overleftrightarrow{s} \\
\stackrel{s}{s}\end{array}$ & 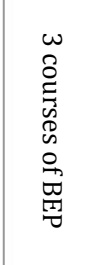 & 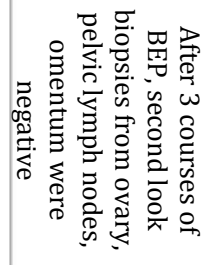 & 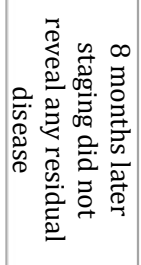 & $\begin{array}{l}z \\
\stackrel{0}{0} \\
\stackrel{0}{0}\end{array}$ & $\begin{array}{l}\text { za } \\
\stackrel{0}{\sigma}\end{array}$ & 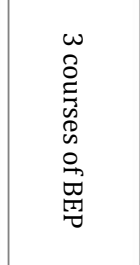 & $\begin{array}{l}z \\
\stackrel{0}{0} \\
\stackrel{0}{0}\end{array}$ & 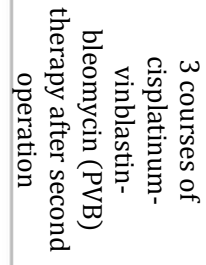 & 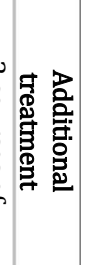 \\
\hline $\begin{array}{l}\text { z } \\
\text { Dे }\end{array}$ & $\begin{array}{l}\text { Z } \\
\stackrel{\Xi}{\sigma}\end{array}$ & $\begin{array}{l}z \\
\text { Z } \\
\vdots\end{array}$ & $\begin{array}{l}z \\
\text { zo } \\
\end{array}$ & $\begin{array}{l}z \\
\text { Z } \\
\stackrel{0}{0}\end{array}$ & $\begin{array}{l}z \\
\stackrel{z}{0} \\
\stackrel{0}{0}\end{array}$ & 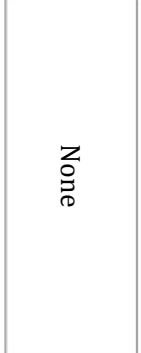 & $\begin{array}{l}\text { z } \\
\text { o } \\
\text { d }\end{array}$ & $\begin{array}{l}z \\
\text { Z } \\
\stackrel{0}{0}\end{array}$ & $\begin{array}{l}z \\
\stackrel{z}{0} \\
\end{array}$ & $\begin{array}{l}z \\
\stackrel{Z}{0}\end{array}$ & 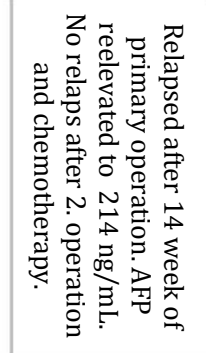 & 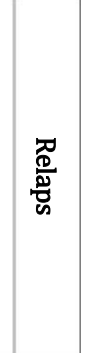 \\
\hline
\end{tabular}




\section{References:}

1. Peterson WF, Prevost EC, Edmunds FT, et al: Benign cystic teratomas of the ovary. A clinico-statistical study of 1,007 cases with a review of the literature. Am J Obstet Gynecol 1955; 70: 368

2. Einarsson JI, Edwards CL, Zurawin RK. Immature ovarian teratoma in an adolescent: a case report and review of the literature.J Pediatr Adolesc Gynecol. 2004; 17(3):187-9.

3. Beiner ME, Gotlieb WH, Korach Y, Shrim A, Stockheim D, Segal Y, Fridman E,Ben-Baruch

G. Cystectomy for immature teratoma of the ovary. Gynecol Oncol. 2004; 93(2):381-4

4. Ulbright TM. Gonadal teratomas: a review and speculation. Adv Anat Pathol. 2004; 11(1):10-23.

5. O'Connor DM, Norris HJ. The influence of grade on outcome of stage I ovarian immature (malignant) teratomas and the reproducibility of grading. Int J Gynecol Pathol 1994; 13:283289.

6. Cushing B, Giller R, Ablin A, Cohen L, Cullen J, Hawkins E, Heifetz SA, Krailo M, Lauer SJ, Marina N, Rao PV, Rescorla F, Vinocur CD, Weetman RM, Castleberry RP. Surgical resection alone is effective treatment for ovarian immature teratoma in children and adolescents: a report of the pediatric oncology group and the children's cancer group. Am J Obstet Gynecol 1999; 181(2):353- 8.

7. Dark GG, Bower M, Newlands ES, Paradinas F, Rustin GJ. Surveillance policy for stage I ovarian germ cell tumors. J Clin Oncol 1997; 15(2):620-4.

8. Bonazzi C, Peccatori F, Colombo N, Lucchini V, Cantu MG, Mangioni C. Pure ovarian immature teratoma, a unique and curable disease: 10 years' experience of 32 prospectively treated patients. Obstet Gynecol 1994; 84(4):598- 604.

9. Heifetz SA, Cushing B, Giller R, Shuster JJ, Stolar CJ, Vinocur CD, Hawkins EP. Immature teratomas in children: pathologic considerations: a report from the combined Pediatric Oncology Group/Children's Cancer Group. Am J Surg Pathol 1998; 22:1115-1124

10. Hamada Y, Tanano A, Sato M, Tsuji M, Sakaida N, Okamura A, Hioki K. Ovarian teratoma with gliomatosis peritonei: report of two cases. Surg Today. 1998; 28(2):223-6

11. Muller AM, Sondgen D, Strunz R, et al. Gliomatosis peritonei: a report of two cases and review of the literature. Eur J Obstet Gynecol Reprod Biol. 2002; 100:213.

12. Moukarram H, Chia KV. Conservative treatment of an immature ovarian teratoma with gliomatosis peritonei. J Obstet Gynaecol, 2006; 26(3):277-8 